\title{
Rotor Position and Velocity Estimation for a Salient-Pole Permanent Magnet Synchronous Machine at Standstill and High Speeds
}

\author{
Matthew J. Corley and Robert D. Lorenz, Fellow, IEEE
}

\begin{abstract}
This paper addresses self-sensing ("sensorless") control of salient-pole permanent magnet synchronous motors (PMSM's). The major contribution of this work is the introduction of a simple-to-implement estimation technique that operates over a wide speed range, including zero speed. The technique achieves simplicity by decoupling the inherent cross-coupling in PMSM's. The technique utilizes the dependence of inductance on rotor position in interior permanent magnet machines to produce position and velocity estimates both for field orientation and for all motion control of the drives. The technique functions in a manner similar to a resolver and resolver-to-digital converter (RTDC) sensing system, whereby in the proposed technique the motor acts as the electromagnetic resolver and the power converter applies carrier-frequency voltages to the stator which produce high-frequency currents that vary with position. The sensed currents are then processed with a heterodyning technique that produces a signal that is approximately proportional to the difference between the actual rotor position and an estimated rotor position. This position error signal and a torque estimate are then used as inputs to a Luenberger style observer to produce parameter insensitive, zero lag, position and velocity estimates.
\end{abstract}

Index Terms - Permanent magnet motor control, self sensing, sensorless control, sensorless tranducerless field orientation, sensorless vector control, transducerless control.

\section{NOMENCLATURE}

\section{Superscripts}

Estimated quantities.

* Commanded quantities.

$s$ Stator reference frame.

$r$ Rotor reference frame.

$\hat{\theta}_{r}$ Estimated rotor reference frame.

Paper IPCSD 98-26, presented at the 1996 Industry Applications Society Annual Meeting, San Diego, CA, October 6-10, and approved for publication in the IEEE TRANSACTIONS ON INDUSTRY APPLICATIONS by the Industrial Drives Committee of the IEEE Industry Applications Society. This work was supported by the Wisconsin Electric Machines and Power Electronics Consortium (WEMPEC), University of Wisconsin, Madison. Manuscript released for publication March 13, 1998.

M. J. Corley was with Marquip, Inc., Madison, WI 53703 USA. He is now with the Federal Division, Maxwell Technologies, San Diego, CA 92123-1506 USA.

R. D. Lorenz is with the Department of Electrical Engineering, University of Wisconsin, Madison, WI 53706-1572 USA.

Publisher Item Identifier S 0093-9994(98)04915-9.

\section{Symbols and Abbreviations}

$\begin{array}{ll}v_{q s}, v_{d s} & \text { Stator } q \text {-and } d \text {-axes voltages. } \\ i_{q s}, i_{d s} & \text { Stator } q \text { - and } d \text {-axes currents. } \\ \lambda_{q s}, \lambda_{d s} & \text { Stator } q \text {-and } d \text {-axes flux linkages. } \\ \lambda_{\mathrm{pm}} & \text { Permanent magnet flux linkage. } \\ L_{q}, L_{d} & \text { Stator } q \text { - and } d \text {-axes inductances. } \\ r_{s} & \text { Stator resistance. } \\ p & \text { Derivative operator. } \\ \omega_{r}, \theta_{r} & \text { Rotor angular velocity and position. } \\ \omega_{i} & \text { Injected carrier signal frequency. } \\ L, \Delta L & \text { Average and differential spatial inductances. } \\ v_{q s i}, v_{d s i} & \text { Stator } q \text {-and } d \text {-axes injected carrier-frequency } \\ i_{q s i}, i_{d s i} & \text { voltages. } \\ \lambda_{q s i}, \lambda_{d s i} & \text { Stator } q \text { - and } d \text {-axes injected carrier-frequency } \\ & \text { Stator } q \text {-and } d \text {-axes injected carrier-frequency } \\ \text { BPF } & \text { flux linkages. } \\ J & \text { Bandpass filter. } \\ T_{e} & \text { Rotor inertia. } \\ & \text { Electromagnetic torque. }\end{array}$

\section{INTRODUCTION}

$\mathbf{F}$ OR PROPER motion and field-oriented control of permanent magnet synchronous motors (PMSM's), knowledge of position and velocity is required. In general, these feedback signals come from feedback devices mechanically coupled to the rotor. This coupling, as well as the electrical connectors and signal wires from the sensor to the controller, reduce the mechanical robustness of the overall system. This reduction in mechanical robustness and the cost of the sensors make elimination of these devices very desirable.

In recent years, numerous papers have been published that address the elimination of the mechanical sensors [1]-[17]. These techniques have been primarily based on the fundamental component voltage model of the machine [1]-[12] or on the spatial inductance of salient rotor machines [1], [13]-[17]. The fundamental component model techniques rely on the position and velocity dependency of the back EMF of the motor. Because back EMF is zero amplitude at standstill, there is a lower limit on the rotor velocity for which these techniques can operate. The methods based on spatial inductance variations have the desired effect that they can operate at zero speed, however, at present, many of these techniques have an upper 


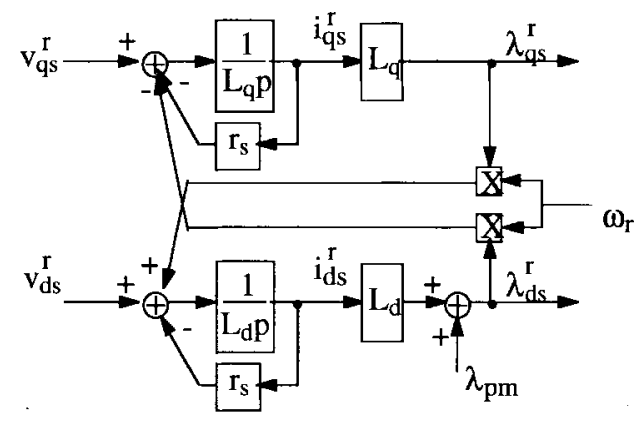

Fig. 1. Model of PM synchronous machine in the rotor reference frame.

limit on the operating speed range due to effects of back EMF at high speeds.

Jansen and Lorenz [15], [17] proposed an estimation technique for the induction machine that utilizes an injected signal at a high frequency to extract position estimates from a machine that has a high-frequency saliency introduced to its rotor. This technique was also used on machines with inherent saliency, such as a buried magnet permanent magnet synchronous (PMS) machine [16]. Such a method has the desired zero- and high-speed properties. However, it relies on a sinusoidal variation in the inductance of the machine. Variations from a sinusoidal inductance profile result in additional complexity in estimating rotor position.

The method proposed here is similar to the one proposed by Jansen and Lorenz in that it utilizes an injected signal at known frequency to extract information from a spatial saliency. However, the method described here relies on the fact that, in a rotor reference frame, the $d$ and $q$ axes of the motor are decoupled from each other. This reduces the number of additional functions that are needed to produce the position estimate.

\section{PM SYNCHRONOUS MACHINE MODEL}

The $d-q$ model for a PM synchronous machine in the rotor reference frame is very helpful in developing the analytical basis for the proposed method of position estimation. The stator voltage model in a rotor reference frame is characterized by (1):

$$
\left[\begin{array}{l}
v_{q s}^{r} \\
v_{d s}^{r}
\end{array}\right]=\left[\begin{array}{cc}
r_{s} & 0 \\
0 & r_{s}
\end{array}\right]\left[\begin{array}{l}
i_{q s}^{r} \\
i_{d s}^{r}
\end{array}\right]+\left[\begin{array}{cc}
p & \omega_{r} \\
-\omega_{r} & p
\end{array}\right]\left[\begin{array}{l}
\lambda_{q s}^{r} \\
\lambda_{d s}^{r}
\end{array}\right]
$$

where $v_{q s}^{r}, v_{d s}^{r}, \lambda_{q s}^{r}, \lambda_{d s}^{r}$, and $i_{q s}^{r}, i_{d s}^{r}$ are the stator $q^{-}$and $d$-axes voltage, flux linkage, and current in the rotor reference frame, $r_{s}$ is the stator resistance, $\omega_{r}$ is the rotor angular velocity, and $p$ is the derivative operator.

The stator flux linkage viewed in a rotor reference frame is given by (2):

$$
\left[\begin{array}{l}
\lambda_{q s}^{r} \\
\lambda_{d s}^{r}
\end{array}\right]=\left[\begin{array}{cc}
L_{q} & 0 \\
0 & L_{d}
\end{array}\right]\left[\begin{array}{l}
i_{q s}^{r} \\
i_{d s}^{r}
\end{array}\right]+\left[\begin{array}{c}
0 \\
\lambda_{\mathrm{pm}}
\end{array}\right]
$$

where $L_{q}$ and $L_{d}$ are the $q$ - and $d$-axes inductance and $\lambda_{\mathrm{pm}}$ is the permanent magnet flux.

Fig. 1 shows this model in block diagram format.

In a rotor reference frame, the $q$-axis flux is produced by the $q$-axis current and the $d$-axis flux is the sum of the flux produced by the $d$-axis current and the flux from the permanent magnets. If the speed voltage is decoupled, then the two axes are decoupled from each other. Thus, a change in the $q$-axis flux should have no effect on the $d$-axis current. This property can be utilized to track the position of the rotor.

\section{PRinciPles of A NeW Estimation Method}

The technique functions in a manner similar to a resolver and resolver-to-digital converter (RTDC) sensing system, whereby, in the proposed technique, the motor acts as the electromagnetic resolver and the power converter applies carrier-frequency voltages to the stator which produce highfrequency currents that vary with position. The sensed currents are then processed with a heterodyning technique that produces a signal that is approximately proportional to the difference between the actual rotor position and an estimated rotor position. This carrier-frequency sensing operation is, of course, occurring simultaneously with the fundamental component power conversion in the motor/power converter.

A sensing approach based on the property of the $q$ - and $d$ axes flux being decoupled can be formulated as follows. If a flux vector at a known carrier frequency is applied only in the $q$ axis of an estimated rotor position, the estimated position can be made to track the actual position via a controller which drives the estimated position such that the $d$-axis current at the injected carrier frequency is zero in the estimated position reference frame.

The injected flux vector in the $q$-axis of the estimated position, $\hat{\theta}_{r}$, reference frame vector can be described by

$$
\left[\begin{array}{c}
\lambda_{q s i}^{\hat{\theta}_{r}} \\
\lambda_{d s i}^{\hat{\theta}_{r}}
\end{array}\right]=\frac{V_{s i}}{\omega_{i}} \sin \left(\omega_{i} t\right)\left[\begin{array}{l}
1 \\
0
\end{array}\right]
$$

where $\omega_{i}$ is the carrier frequency of the injected signal, and $V_{s i} / \omega_{i}$ is the magnitude of the injected flux vector.

Transforming the flux vector to the stationary reference frame yields

$$
\left[\begin{array}{l}
\lambda_{q s i}^{s} \\
\lambda_{d s i}^{s}
\end{array}\right]=\frac{V_{s i}}{\omega_{i}} \sin \left(\omega_{i} t\right)\left[\begin{array}{c}
\cos \left(\hat{\theta}_{r}\right) \\
-\sin \left(\hat{\theta}_{r}\right)
\end{array}\right]
$$

The carrier-frequency stator flux linkage in a stationary reference frame is given by

$$
\left[\begin{array}{l}
\lambda_{q s i}^{s} \\
\lambda_{d s i}^{s}
\end{array}\right]=\left[\begin{array}{cc}
L+\Delta L \cos \left(2 \theta_{r}\right) & -\Delta L \sin \left(2 \theta_{r}\right) \\
-\Delta L \sin \left(2 \theta_{r}\right) & L-\Delta L \cos \left(2 \theta_{r}\right)
\end{array}\right]\left[\begin{array}{l}
i_{q s i}^{s} \\
i_{d s i}^{s}
\end{array}\right]
$$

where $i_{q s i}^{s}$ and $i_{d s i}^{s}$ are the carrier-frequency components of the stator current in a stationary frame and $L$ and $\Delta L$ are the average inductance and the amplitude of the spatial modulation of the inductance, as defined by

$$
L=\frac{L_{q}+L_{d}}{2}, \quad \Delta L=\frac{L_{q}-L_{d}}{2} .
$$

The carrier-frequency components of the stator currents in a stationary frame can be obtained from (4) and (5), resulting in

$$
\left[\begin{array}{c}
i_{q s i}^{s} \\
i_{d s i}^{s}
\end{array}\right]=\sin \left(\omega_{i} t\right)\left[\begin{array}{c}
I_{i 0} \cos \left(\hat{\theta}_{r}\right)-I_{i 1} \cos \left(2 \theta_{r}-\hat{\theta}_{r}\right) \\
-I_{i 0} \sin \left(\hat{\theta}_{r}\right)+I_{i 1} \sin \left(2 \theta_{r}-\hat{\theta}_{r}\right)
\end{array}\right]
$$




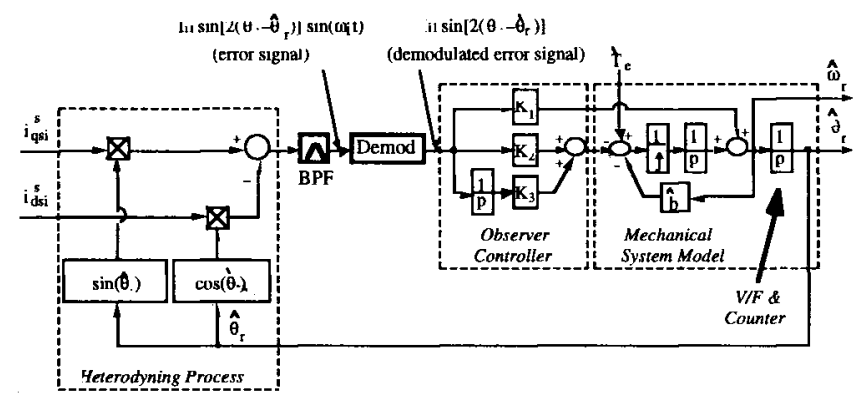

Fig. 2. Observer block diagram.

where the high-frequency current magnitudes $I_{i 0}$ and $I_{i 1}$ are defined by

$$
I_{i 0}=\frac{V_{s i}}{\omega_{i}} \frac{L}{L^{2}-\Delta L^{2}} \quad I_{i 1}=\frac{V_{s i}}{\omega_{i}} \frac{\Delta L}{L^{2}-\Delta L^{2}} .
$$

The $d$-axis component of the high-frequency current in the estimated rotor position reference frame is given by

$$
i_{d s i}^{\hat{\theta}_{r}}=i_{q s i}^{s} \sin \left(\hat{\theta}_{r}\right)+i_{d s i}^{s} \cos \left(\hat{\theta}_{r}\right)
$$

which results in

$$
i_{d s i}^{\hat{\theta}_{r}}=\sin \left(\omega_{i} t\right) I_{i 1} \sin \left[2\left(\theta_{r}-\hat{\theta}_{r}\right)\right] .
$$

From (10), it can be seen that a carrier-frequency signal is produced that is amplitude modulated by the error between the estimated position and the actual position. This signal takes on the same form as the error signal generated internally by the standard RTDC. Thus, position information can be extracted in the same manner as an RTDC. First, the signal is demodulated to form a dc signal proportional to the error, and then this error is fed into an observer that updates the estimated velocity and position to force the error to zero. A block diagram of the observer and the heterodyning process is given in Fig. 2.

The observer is based on the model of the mechanical system of the motor. It uses an estimate of the torque and inertia of the motor to estimate the velocity and position of the rotor. With a correct inertia estimate, the estimated velocity and position will track the actual velocity and position under acceleration with zero lag. The error signal generated by the heterodyning process is used to correct the estimates under load changes and to compensate for inertia estimate errors during speed transients.

Because we can directly manipulate the voltage applied to the machine, we calculate the voltage command feedforward needed to generate the desired decoupled flux vector in (3) and (4). Since the stator resistive voltage drop is small relative to the induced voltage at the injected frequency, the stationary frame voltage that must be applied to the stator can be well approximated by

$$
\left[\begin{array}{c}
v_{q s i}^{s} \\
v_{d s i}^{s}
\end{array}\right] \approx\left[\begin{array}{cc}
p & 0 \\
0 & p
\end{array}\right]\left[\begin{array}{c}
\lambda_{q s i}^{s} \\
\lambda_{d s i}^{s}
\end{array}\right]
$$

This results in

$\left[\begin{array}{c}v_{q s i}^{s} \\ v_{d s i}^{s}\end{array}\right]=V_{s i}\left(\cos \left(\omega_{i} t\right)\left[\begin{array}{c}\cos \left(\hat{\theta}_{r}\right) \\ -\sin \left(\hat{\theta}_{r}\right)\end{array}\right]-\sin \left(\omega_{i} t\right) \frac{\hat{\omega}_{r}}{\omega_{i}}\left[\begin{array}{c}\sin \left(\hat{\theta}_{r}\right) \\ \cos \left(\hat{\theta}_{r}\right)\end{array}\right]\right)$.

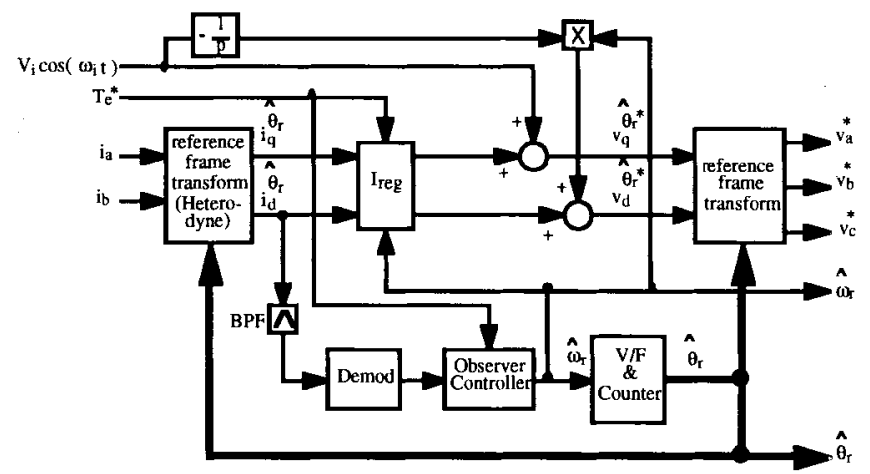

Fig. 3. System block diagram.

Since the control is easier to implement in the rotor frame, it is best to transform these equations to the estimated rotor frame, designated by the superscript $\hat{\theta}_{r}$, as follows. Rewriting (11), we obtain

$$
\left[\begin{array}{c}
v_{q s i}^{\hat{\theta}_{r}} \\
v_{d s i}^{\hat{\theta}_{r}}
\end{array}\right]=\left[\begin{array}{cc}
p & \hat{\omega}_{r} \\
-\hat{\omega}_{r} & p
\end{array}\right]\left[\begin{array}{c}
\lambda_{q s i}^{\hat{\theta}_{r}} \\
\lambda_{d s i}^{\hat{\theta}_{r}}
\end{array}\right] .
$$

Substituting (3), one can remove the flux variables

$$
\left[\begin{array}{c}
v_{q s i}^{\hat{\theta}_{r}} \\
v_{d s i}^{\hat{\theta}_{r}}
\end{array}\right]=\left[\begin{array}{cc}
p & \hat{\omega}_{r} \\
-\hat{\omega}_{r} & p
\end{array}\right] \frac{V_{s i}}{\omega_{i}} \sin \left(\omega_{i} t\right)\left[\begin{array}{l}
1 \\
0
\end{array}\right] .
$$

After simplification, the voltage command feedforward terms become a very simple set

$$
\left[\begin{array}{c}
v_{q s i}^{\hat{\theta}_{r}} \\
\hat{\theta}_{d s i} \\
v_{d s i}
\end{array}\right]=V_{s i}\left[\begin{array}{c}
\cos \left(\omega_{i} t\right) \\
-\frac{\hat{\omega}_{r}}{\omega_{i}} \sin \left(\omega_{i} t\right)
\end{array}\right] .
$$

Fig. 3 depicts the system with the generation of these highfrequency voltage commands. This figure also includes a block for a current regulator $\left(I_{\text {reg }}\right)$. From the diagram, it can be seen that, if the current regulation is going to be done in a synchronous frame, only a modest amount of additional functions are needed to produce the position estimate.

This topology for estimating rotor position has some very attractive features. First, its steady-state tracking ability is not dependent on the motor parameters. The term $I_{i 1}$ is dependent on the inductance of the motor. However, this term is only a scaling term and should not affect the accuracy of the position and velocity estimates, since its spatial angle is being tracked, not the amplitude. Second, the magnitude of $I_{i 1}$ is also independent of velocity, thus, the observer eigenvalues will be independent of speed if a linear observer controller is used. The independence of $I_{i 1}$ from velocity also gives this estimation technique the inherent ability to work at standstill.

\section{EXPERIMENTAL RESULTS}

\section{A. Experimental Motor}

The motor used in the development of the experimental system is a buried magnet PMS motor. This motor is designed to be used in servo motor applications and, thus, is deemed 
TABLE I

Electrical and Mechanical Specifications of Experimental Motor

\begin{tabular}{ll}
\hline Stall Torque & $367 \mathrm{oz}$ in \\
Speed & $6200 \mathrm{r} / \mathrm{min}$ (maximum continuous) \\
Rated Current & $5-\mathrm{A} \mathrm{rms}$ \\
$K_{t}$ & $68.7 \mathrm{oz} \mathrm{in} / \mathrm{A} \mathrm{rms}$ \\
$K_{e}$ & $29.4 \mathrm{~V} / \mathrm{kr} / \mathrm{min}$ (rms volts of line-to-line sine \\
$R$ & wave) \\
$L$ & $2.3 \Omega \mathrm{phase}$ to phase \\
$J$ & $25 \mathrm{mH}+/-30 \%$ (phase to phase) \\
\hline
\end{tabular}

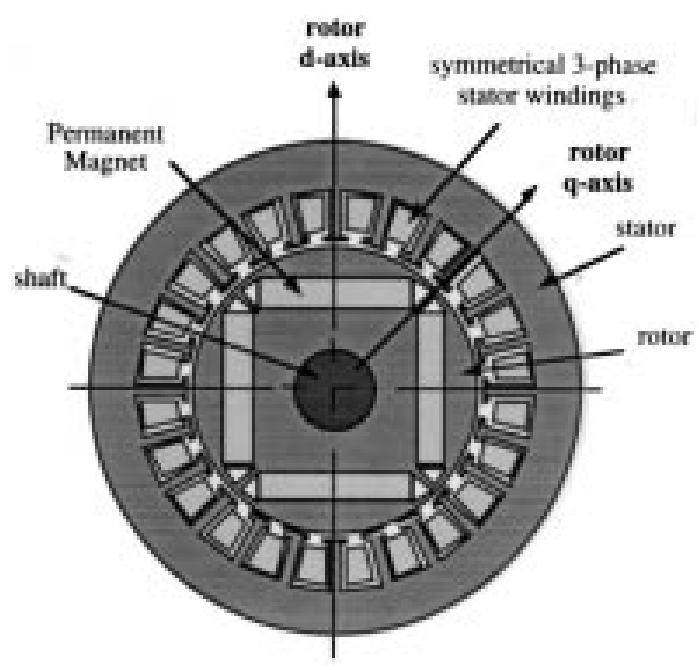

Fig. 4. Buried magnet PMS motor cross section.

an appropriate motor to study. The electrical and mechanical data for this motor are given in Table I.

A cross section of the motor used in the experimental tests is given in Fig. 4. It can be seen from this figure that the motor has a four-pole rotor with inset permanent magnets. Imbedding the magnets in the rotor provides a more mechanically robust rotor capable of higher speed operation compared to a rotor with magnets mounted on the surface of the rotor. A rotor constructed in this way also results in a rotor $q$-axis inductance that is larger than the $d$-axis inductance. The flux in the $d$ axis of the motor must cross the magnet airgap as well as the physical airgap, whereas the $q$-axis flux can take a path through the pole face of the rotor, requiring the flux to only cross the physical airgap. This results in a rotor $q$-axis inductance that is greater than the $d$-axis inductance.

Fig. 5 shows the self inductance of the stator $d$ axis versus rotor position. From this picture, it can be seen that this motor contains a great deal of saliency.

\section{B. Implementation of Position Estimation}

The actual implementation of the technique involved the use of two Analog Devices AD2S100 vector rotator chips to perform the reference frame transformation and an RTDC to perform the voltage to frequency $(\mathrm{V} / \mathrm{F})$ and counter operation. The demodulation was done by multiplying the high-frequency signal by a signal at the injected frequency to produce a signal that consisted of a dc portion proportional to the error, as well

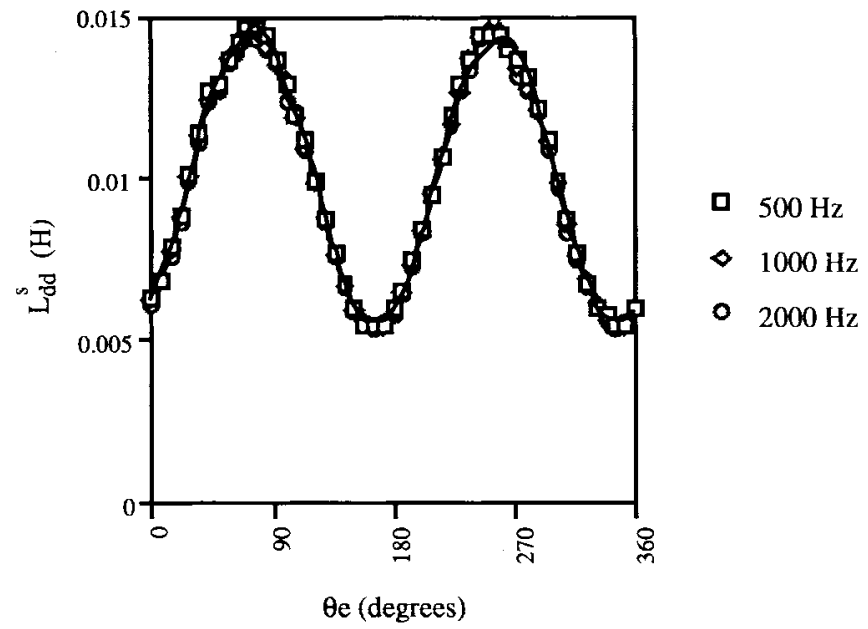

Fig. 5. Self inductance of the stator $d$ axis versus rotor position.

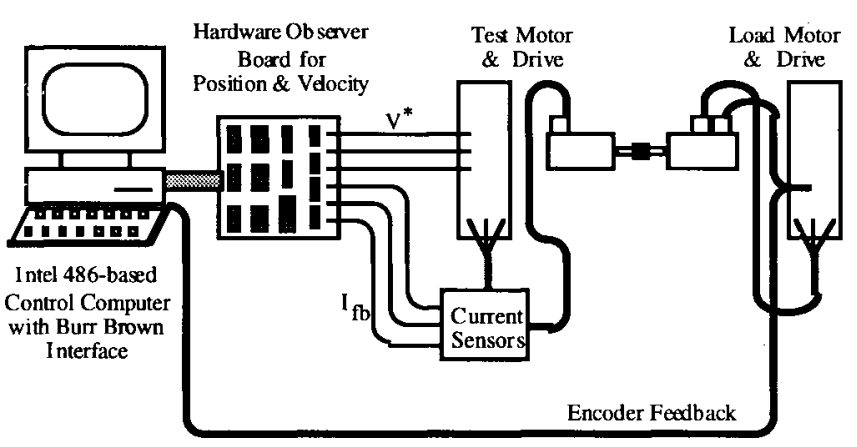

Fig. 6. Experimental, dual motor drive test setup.

as a component at twice the injected frequency. The twicefrequency component is only present when the system is not tracking correctly.

\section{Experimental Test Setup}

The experimental setup used for this research is the dual motor drive system depicted in Fig. 6.

The dual motor drive configuration was set up to allow continuous and transient loads to be applied at any speed. Such a configuration is quite helpful in evaluating self-sensing methods over a full range of operating conditions, including sustained zero and very-low-speed loaded operation.

The setup consists of an Intel 486-based personal computer with a Burr Brown interface board consisting of an eightchannel analog-to-digital converter board, two two-channel digital-to-analog converter boards, and four 8-b digital I/O ports. In addition, the computer also contains an encoder interface board for comparison of actual position with the estimated position. The position and velocity estimation is performed in hardware and is interfaced to the computer via the Burr Brown interfaces. The computer is used to perform the current regulation and motion control. The setup also consists of an Electrocraft BRU 200 drive connected to the test motor. This drive has been modified to allow for direct access to the voltage command points, thus disabling its hardware current regulator in favor or our synchronous frame digital regulator. 


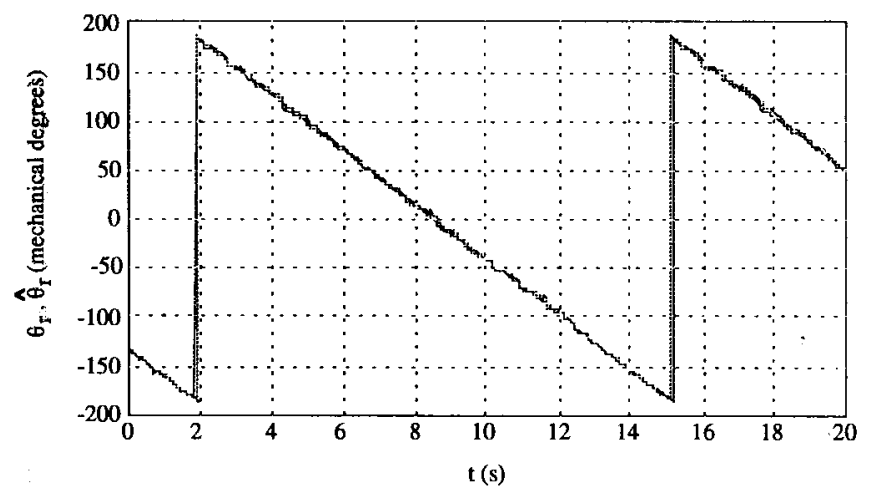

Fig. 7. Estimated and measured position at $4.6 \mathrm{r} / \mathrm{min}$.

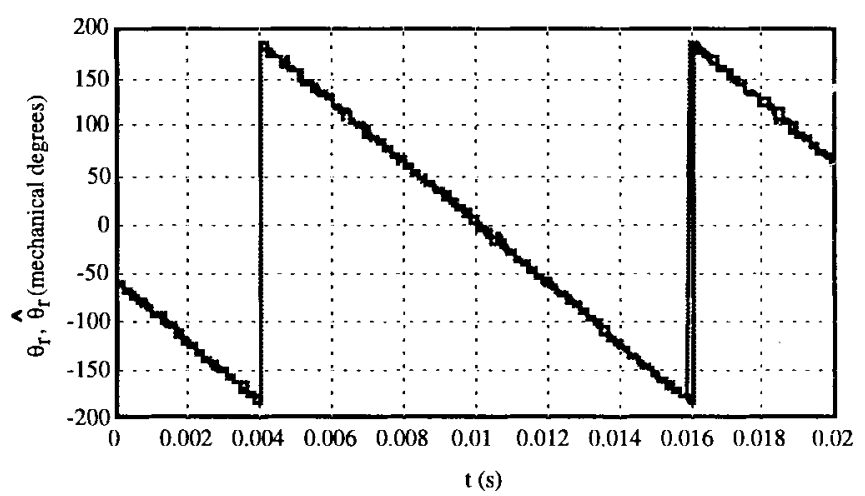

Fig. 8. Estimated and measured position at $5000 \mathrm{r} / \mathrm{min}$.

The test motor is coupled to a load motor that is controlled with another Electrocraft BRU 200 drive. This drive has not been modified and uses an encoder for feedback from the motor. This encoder feedback from the load motor is also fed to the control computer for test purposes only. This encoder is a 2000-line encoder, which yields 8000 counts per revolution of the motor. Both drives operate with switching frequencies of $10 \mathrm{kHz}$ and a 2-kHz carrier frequency used for the estimation.

The magnitude of the carrier-frequency voltage is set at $10 \%$ of rated voltage, resulting in a current at the carrier frequency of about $2 \%$ rated current. This results in a $2 \%$ torque oscillation. Because this torque oscillation is at $2 \mathrm{kHz}$, the inertia of the motor very effectively filters the effect of this very small carrier-frequency torque to negligible levels on the motor velocity.

The observer is tuned for a $100-\mathrm{Hz}$ bandwidth. This and the observer feedforward input give fast response in estimated velocity and position under dynamic load changes.

\section{Experimental Data}

Fig. 7 shows the estimated and actual position measured with an encoder at low speed. Fig. 8 shows the estimated and actual position measured with an encoder at high speed. These two figures show the tracking ability of estimation at low and high speeds.

This estimation method relies on the property of the $q$ and $d$ axes being decoupled in the rotor reference frame. However, under load, saturation of the machine can cause the reference angle to move away from the rotor zero angle. Figs. 9-11

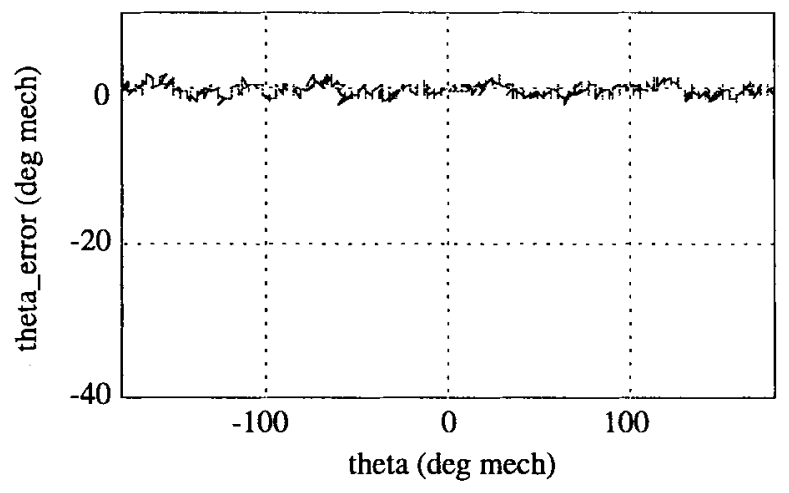

Fig. 9. Position error versus position at no load.

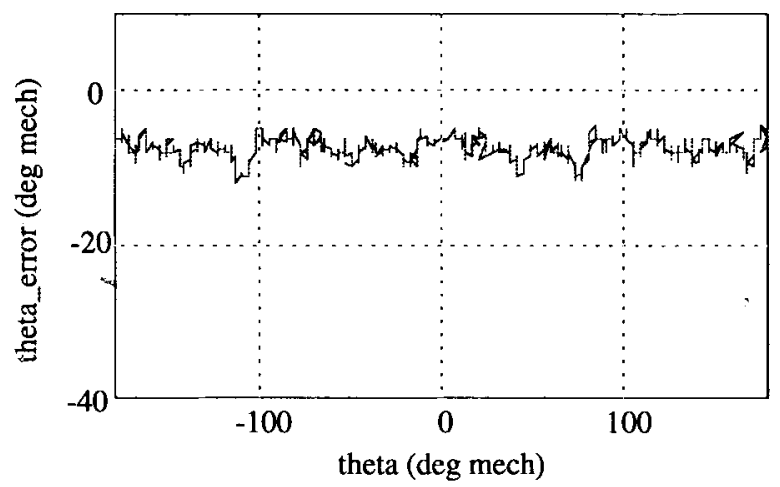

Fig. 10. Position error versus position at a 3-A load.

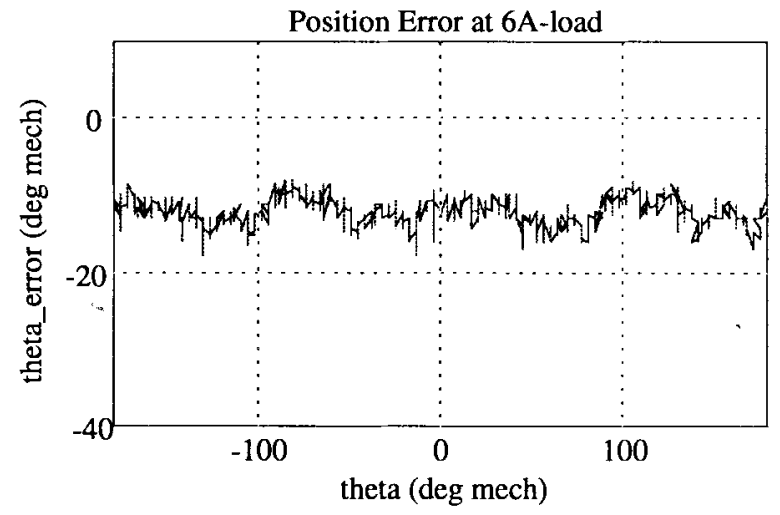

Fig. 11. Position error versus position at a 6-A load.

demonstrate the effect that this has on the accuracy of the estimated position. This effect can be seen as a predictable offset in the position estimate which is easily compensated. One simple, but effective, method for compensation is with a position correction term that is a linear function of current.

Figs. 9-11 show that there also exists some load-dependent error that is harmonic with position. It is believed that this error is related to unmodeled saliencies. Without including such unmodeled terms in the shape being tracked, this harmonic error can cause localized instability and oscillation if the gains on velocity and position are set too high. The experimental system was limited to a $10-\mathrm{Hz}$ velocity loop. With the single-saliency model, the use of the position and velocity information is limited to commutation or low-performance servo applications. 


\section{CONCLUSION}

This paper has introduced a self-sensing technique for estimating position and velocity for PMSM's, which is appropriate for both standstill and high speeds. The approach utilizes the inherent cross coupling in PMSM's to achieve a very simple implementation. The estimated position and velocity are used for field orientation of the motor, as well as for closing position and velocity loops. It has been demonstrated experimentally that this technique is accurate over a wide speed range of operation, including zero speed. The load-dependent error which arises when using this technique has been shown to be predictable and is, thus, easily compensated.

\section{REFERENCES}

[1] M. Schroedl, "An improved position estimator for sensorless control of permanent magnet synchronous motors," in Proc. EPE'91, 1991, vol. 3, pp. 418-423.

[2] R. Wu and G. Slemon, "A permanent magnet motor drive without a shaft sensor," IEEE Trans. Ind. Applicat., vol. 27, pp. 1005-1011, Sept./Oct. 1991.

[3] M. Jufer and R. Osseni, "Back EMF indirect detection for selfcommutation of synchronous motors," in Proc. EPE'87, 1987, vol. 2, pp. 1125-1129.

[4] N. Ertugrul and P. Acarnley, "A new algorithm for sensorless operation of permanent magnet motors," in Conf. Rec. IEEE-IAS Annu. Meeting, 1992, vol. 1, pp. 414-421.

[5] N. Matsui and M. Shigyo, "Brushless DC motor control without position and speed sensors," IEEE Trans. Ind. Applicat., vol. 28, pp. 120-127, Jan./Feb. 1992.

[6] J. Davoine, R. Perret, and H. Le-Huy, "Operation of a self-controlled synchronous motor without a shaft position sensor," IEEE Trans. Ind. Applicat., vol. IA-19, pp. 217-222, Mar./Apr. 1983.

[7] K. Iizuka, H. Uzuhashi, M. Kano, T. Endo, and K. Mohri, "Microcomputer control for sensorless brushless motor," IEEE Trans. Ind. Applicat., vol. IA-21, pp. 595-601, May/June 1985.

[8] R. C. Becerra, T. M. Jahns, and M. Ehsani, "Four-quadrant sensorless brushless ECM drive," in Proc. APEC'91, 1991, pp. 202-209,

[9] S. Ogasawara and H. Akagi, "An approach to position sensorless drive for brushless DC motors," IEEE Trans. Ind. Applicat., vol. 27, pp. 928-933, Sept./Oct. 1991.

[10] O. Shinkawa, K. Tabata, A. Uetake, T. Shimoda, S. Ogasawara, and H. Akagi, "Wide speed operation of a sensorless brushless DC motor having an interior permanent magnet rotor," in Proc. PCC-Yokohama'93, 1993, pp. 364-370.

[11] L. Jones and J. Lang, "A state observer for the permanent-magnet synchronous motor," IEEE Trans. Ind. Electron., vol. 36, pp. 374-382, Aug. 1989.

[12] G. Henneberger, B.-J. Brunsbach, and T. Klepsch, "Field-oriented control of synchronous and asynchronous drives without mechanical sensors using a Kalman filter," in Proc. EPE'91, 1991, vol. 3, pp. 664-671.

[13] A. Kulkarni and M. Ehsani, "A novel position sensor elimination technique for the interior permanent-magnet synchronous motor drive," IEEE Trans. Ind. Applicat., vol. 28, pp. 144-150, Jan./Feb. 1992.

[14] K. Binns, D. Shimmin, and K. Al-Aubidy, "Implicit rotor-position sensing using motor windings for a self-commutating permanent-magnet drive system," Proc. Inst. Elect. Eng., vol. 138, pt. B, no. 1, pp. 28-34, Jan. 1991.
[15] P. L. Jansen and R. D. Lorenz, "Transducerless position and velocity estimation in induction and salient AC machines," IEEE Trans. Ind. Applicat., vol. 31, pp. 240-247, Mar./Apr. 1995.

[16] P. L. Jansen, M. Corley, and R. D. Lorenz, "Flux, position, and velcoity estimation in AC machines at zero speed via tracking of high frequency saliencies," in Proc. EPE'95, 1995, pp. 154-160.

[17] P. L. Jansen and R. D. Lorenz, "Transducerless field orientation concepts employing saturation-induced saliencies in induction machines," in Conf. Rec. IEEE-IAS Annu. Meeting, 1995, pp. 174-181.

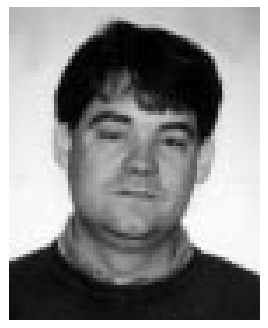

Matthew J. Corley was born in Kingston, NY, in 1968. He received the B.S.E.C.E. and M.S.E.E. degrees from the University of Wisconsin, Madison, in 1990 and 1993, respectively.

During his M.S. program, he was both a Teaching and a Research Assistant at the University of Wisconsin, Madison. From 1995 to March 1998 , he was a Design Engineer in the Power Electronics Group, Marquip, Inc., Madison, WI, where he worked on the design of ac PWM servo drives for use in corrugated machinery. He then joined Maxwell Technologies, San Diego, CA, where he is currently a Design and Development Engineer for power quality systems.

Mr. Corley is a member of Theta Tau and Tau Beta Pi.

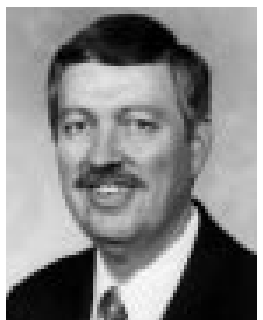

Robert D. Lorenz (S'83-M'84-SM'91-F'98) received the B.S., M.S., and Ph.D. degrees from the University of Wisconsin, Madison, in 1969, 1970, and 1984, respectively.

Since 1984, he has been a Member of the Faculty of the University of Wisconsin, Madison, where he is currently a Professor of Mechanical Engineering and of Electrical and Computer Engineering. In this position, he acts as Co-Director of the Wisconsin Electric Machines and Power Electronics Consortium and as Co-Director of the Advanced Automation and Robotics Consortium. He is also an active Consultant to many organizations. He was a Visiting Research Professor in the Electrical Drives Group of the Catholic University of Leuven, Leuven, Belgium, in the summer of 1989 and in the Power Electronics and Electrical Drives Institute of the Technical University of Aachen, Aachen, Germany, in the summers of 1987, 1991, 1995, and 1997. In 1969-1970, he conducted his Master's thesis research at the Technical University of Aachen. From 1972 to 1982, he was a Member of the Reseach Staff at the Gleason Works, Rochester, NY. His current research interests include sensorless electromagnetic motor/actuator technologies, real-time signal processing and estimation techniques, precision multiaxis motion control, and ac drive and high-precision machine control technologies.

Dr. Lorenz is currently Chair of the IEEE Industry Applications Society (IAS) Awards Department, a member and past Chairman of the IAS Industrial Drives Committee, and a member of the IAS Electrical Machines Committee, the IAS Industrial Power Converter Committee, and the IAS Industrial Automation and Control Committee. He is a Registered Professional Engineer in the States of New York and Wisconsin. He is also a member of the American Society of Mechanical Engineers, Instrument Society of America, and Society of Photo-Optical Instrumentation Engineers. 